\title{
Factors associated with the development of skin allergies in premature newborns in the first year of life
}

\author{
Fatores associados ao desenvolvimento de alergias de pele \\ em prematuros no primeiro ano de vida \\ Factores asociados con el desarrollo de alergias a la piel \\ en prematuras en el primer año de vida
}

\section{How to cite this article:} Jantsch, LB, Bridi BPL, Higashi GDC, Arrué AM, Oliveira DC, Neves ET. Factors associated with the development of skin allergies in premature newborns in the first year of life. Rev Gaúcha Enferm. 2021;42:e20200261. doi: https://doi. org/10.1590/1983-1447.2021.20200261 aniversidade Federal de Santa Maria (UFSM), Departamento de Ciências da Saúde. Palmeira das Missōes, Rio Grande do Sul, Brasil.

b Universidade Federal de Santa Maria (UFSM), Curso de Enfermagem. Palmeira das Missões, Rio Grande do Sul, Brasil.

Universidade Federal do Paraná (UFPR), Programa de Pós-Graduação em Enfermagem, Curitiba, Paraná, Brasil.

${ }^{d}$ Universidade Federal de Santa Maria (UFSM), Curso de Enfermagem, Santa Maria, Rio Grande do Sul, Brasil.

e Universidade Federal de Santa Maria (UFSM), Departamento de Enfermagem, Programa de Pós-Graduaçăo em Enfermagem, da Universidade Federal de Santa Maria, Santa Maria, Rio Grande do Sul, Brasil.

\section{ABSTRACT}

Objective: To identify the factors associated with the development of skin allergies in the first year of life in moderate and late preterm infants.

Method: This is a cross-sectional study with 151 moderate and late preterm infants, born between May 2016 and May 2017. Participants were evaluated in the 3rd, 6th, 9th and 12th months of life, in telephone interviews. Statistical analyzes were performed in the SPSS software with frequency comparison tests and logistic regression.

Results: The prevalence of skin allergy, in the perception of caregivers, among late and moderate preterm infants was 16\%. Factors such as being admitted to neonatal intensive care $(p=0.006)$ and not being breastfed $(p=0.041)$ showed a significant association with the development of skin allergies in the 3rd and 12th months of life, respectively.

Conclusion: Skin allergy, in the perception of caregivers, is more severe in newborn infants who have clinical respiratory and gastrointestinal manifestations, be it conditioning or cause-effect. Breastfeeding proved to be a protective factor in the first year of life. Keywords: Infant, premature. Infant. Skin. Skin manifestations. Risk factors.

RESUMO

Objetivo: Identificar os fatores associados ao desenvolvimento de alergias de pele no primeiro ano de vida em prematuros moderados e tardios.

Método: Trata-se de uma pesquisa seccional, com 151 prematuros moderados e tardios, nascidos entre maio de 2016 e maio de 2017. Os participantes foram avaliados no 30, 60, 90 e $12^{\circ}$ mês de vida, por contato telefônico. As análises estatísticas foram realizadas no software SPSS com testes de comparação de frequência e regressão logística.

Resultados: A prevalência de alergia de pele, na percepção dos cuidadores, entre prematuros tardios e moderados foi de 16\%. Fatores como ser egresso da terapia intensiva neonatal $(p=0,006)$ e não estar em aleitamento materno $(p=0,041)$ mostrou associação significativa no $3^{\circ}$ e $12^{2}$ mês de vida, respectivamente.

Conclusão: A alergia de pele, na percepção dos cuidadores, é uma característica mais intensa naqueles que apresentam manifestações clínicas respiratórias e gastrointestinais, seja ela condicionante ou de causa-efeito. 0 aleitamento materno mostrou-se um fator protetor no $1^{0}$ ano de vida.

Palavras-chave: Recém-nascido prematuro. Lactente. Pele. Manifestações cutâneas. Fatores de risco.

RESUMEN

Objetivo: identificar los factores asociados con el desarrollo de alergias cutáneas en el primer año de vida en prematuros moderados y tardíos.

Método: Este es un estudio en sección con 151 recién nacidos prematuros moderados y tardíos, nacidos entre mayo de 2016 y mayo de 2017. Los participantes fueron evaluados en el tercer, sexto, noveno y duodécimo mes de vida, por contacto telefónico. Análisis estadísticos realizados en el software SPSS con pruebas de comparación de frecuencia y regresión logística.

Resultados: La prevalencia de alergia cutánea, en la percepción de los cuidadores, entre los prematuros tardíos y moderados fue del $16 \%$. Factores como el alta de cuidados intensivos neonatales $(p=0,006)$ y la no lactancia $(p=0,041)$ mostraron asociación significativa en el 30 y $12^{\circ}$ mes de vida, respectivamente.

Conclusión: La alergia cutánea, en la percepción de los cuidadores, es una característica más intensa en quienes presentan manifestaciones clínicas respiratorias y gastrointestinales, ya sea condicionante o causa-efecto. La lactancia materna demostró ser un factor protector en el primer año de vida.

Palabras clave: Recien nacido prematuro. Lactante. Piel. Manifestaciones cutáneas Factores de riesgo. 


\section{口INTRODUCTION}

Nearly 30 million children are born prematurely with low weight and /or get sick every year in the world ${ }^{(1)}$. According to the World Health Organization (WHO), premature infants are babies born alive before 37 weeks of pregnancy. Those born between 32 and 37 weeks are classified as moderate to late preterm infants, and the prevalence of preterm births is nearly $10 \%$ of the total number of live births ${ }^{(1)}$.

Moderate and late preterm infants have health problems that pose higher risk of mortality and morbidity, especially in the first year of life. They consist of a population at higher risk of death or development of chronic health conditions related to prematurity such as brain injury and/or hypoxemia during childbirth, neonatal sepsis, jaundice and/or congenital conditions $s^{(1)}$.

Thus, preterm and low-birth-weight babies require the implementation of practices that guarantee assistance aimed at treating the common medical conditions that affect this population. Skin problems deserve mention as they are prevalent conditions in preterm infants. The skin is the first line of defense against pathogens, which maintains homeostasis, minimizing unnecessary fluid losses and electrolyte imbalances. Regardless of the gestational age of premature babies, special attention should be paid to skin care practices and hygiene, as well as to adherence to exclusive breastfeeding as a protective factor against food allergies and consequent skin injuries ${ }^{(2)}$.

Premature infants have a less developed skin, which is more susceptible to inflammatory response and erosion. The poor adherence of skin strata, especially in premature babies, makes them more vulnerable to skin disorders in their first months of life. It is known that the lower the gestational age at birth, the lower the ability of the skin of newborn infants to provide a protective barrier against skin diseases ${ }^{(2)}$.

In the first year of life, whether babies are premature or not, nutritional and metabolic factors, which are determinant for health and well-being, and the development of skin disorders, especially allergens, are interconnected ${ }^{(3)}$.

Skin disorders, especially eczema and skin allergies, are a public health problem, especially in children born prematurely. These conditions are characterized by an inflammatory process of the skin. They have clinical specificities and can be divided into two types of eczema: atopic dermatitis or contact dermatitis. Atopic eczema, of a hereditary allergic nature, is frequent and is associated with other allergic/ inflammatory manifestations such as asthma, rhinitis and urticaria. Lesions are usually vesicopustular eruptions and/or crusted lesions, located especially on the face, scalp and on the extensor surfaces of the upper or lower limbs. Contact eczema is caused by inflammatory reactions triggered by external agents resulting from primary irritation or secondary sensitization. It is characterized by erythematous, vesicular and/or crusted lesions ${ }^{(4)}$.

In approximately $80 \%$ of the patients who develop atopic eczema, this manifestation occurs in the first year of life ${ }^{(4)}$ and lesions remain throughout adolescence and early adulthood $^{(5)}$. Environmental aspects (pollutants) and food allergies can contribute to the development of eczema ${ }^{(6)}$. However, according to international studies, family history, diseases and complications of the perinatal period, including prematurity and its neonatal complications (jaundice, early antimicrobial exposure, lung diseases), are the main predisposing factors for the development of eczema ${ }^{(7-8)}$.

There are still uncertainties about the relationship and the intrinsic and extrinsic factors in the etiology of dermatitis and eczema, especially in children and infants. Therefore, it is necessary to recognize the associated factors and the necessary factors when the intimate relationship between their prevalence and respiratory and eating/gastrointestinal disorders is recognized ${ }^{(9)}$. This incipient relationship reinforces the need to understand the relationship between skin manifestations and other acute and chronic health problems, especially in the population of moderate and late preterm infants.

The vulnerability of moderate and late preterm infants, which contributes to the development of eczema and skin allergies, is evidenced by the immaturity of their physiological systems, which may cause breathing difficulties, poor regulation of body temperature and other immunity-related complications such as neonatal infections that predispose these preterm infants to skin allergies ${ }^{(7)}$. In contrast, studies suggest that extreme prematurity is inversely correlated to the development of eczema and other dermatitis, which arouses debate and demonstrates that late and moderate preterm infants are a population at risk for skin allergies ${ }^{(10)}$.

Knowledge of the processes of vulnerability of moderate and late preterm infants allows to propose coping strategies and reduce injuries and complications to this specific and prevalent population. Thus, the present study aimed to identify the factors associated with the development of skin allergies in the first year of life in moderate and late preterm infants. 


\section{METHOD}

Cross-sectional study, with analysis of data from a follow-up study, with a population of 151 moderate and late preterm infants, born between May 2016 and May 2017, in a reference hospital for high-risk pregnancies in the central region of Rio Grande do Sul (RS) and who live in the city of Santa Maria/RS. The study was conducted in the above-mentioned period to reduce biased estimates of seasonal health disorders.

In the study setting, 1,371 babies were born during data collection. Of these, 280 (20.4\%) were late and moderate premature infants. The inclusion criteria of this study were preterm infants with gestational age (GA) from 32 to 36 weeks and 6 days (moderate and late), born at the hospital where the study was conducted and who lived in the city of Santa Maria/ RS, at the time of hospital discharge. Therefore, of the 280 moderate and late preterm infants born in the study period, 117 were excluded because they did not live in the municipality. Of the 163 eligible participants, 12 did not accept to participate in the study, totaling 151 moderate and late preterm infants. Study participants were assessed quarterly, from birth to 12 months of age. The health conditions of these infants were assessed over a two-year period beginning in May 2016 and ending in May 2018.

Participants were selected in two stages. In the first stage, all late and moderate preterm infants born during the study period in a hospital were selected. During the entire collection period (May 2016-May 2017) the NICU was visited daily, in the morning and in the afternoon, by researchers specially trained for the study.

Data on the gestational age of newborn infants (determined by the Capurro method in the first 12 hours of life), information on delivery and place of residence were obtained from medical records. During the hospitalization of the newborn infants, family members were invited to participate in the study and were approached in the maternity ward or Neonatal Intensive Care Unit (NICU) (depending on the unit where the NB was admitted). As the NICU encourages contact and shared accommodation between mothers and babies during the entire hospitalization, under the care of the nursing team, the approach was made in these places. In the maternity ward or NICU, parents were informed about the objectives of the study and invited to participate. All signed the informed consent form (ICF). A field coordinator closely monitored data collection at all stages of the study. A form was specifically created for the study and properly tested. It included neonatal and obstetric variables, as well as socioeconomic characteristics.
The infants were evaluated, through telephone interviews at 3,6, 9 and 12 months of life. After three unsuccessful attempts to call (on different days) any family of a newborn, or when the phone number was non-existent, the interview was canceled. At the initial stage, the participants were 151 moderate and late preterm infants (study population). In the third month, 119 children were evaluated [21.2\% loss (1 loss due to death; 31 due to no response by telephone contact)]; in the sixth month, 108 children were evaluated [loss of 28.5\% (there were five more losses due to failed telephone contact attempts; six due to withdrawal from participating in the study)]; at 9 months, 106 children were evaluated [plus two losses, related to loss of contact] and, in the last assessment, at 12 months of age, 105 children participated. Loss of $30 \%$ of the population, a value considered acceptable for epidemiological/longitudinal studies ${ }^{(11)}$.

The neonatal variables analyzed, constructed using the instrument previously tested by the researchers, consisted of: gestational age [Moderate Preterm (32 weeks to 33 weeks and 6 days) Late Preterm (34 weeks to 36 weeks and 6 days)], birth weight ratio (second percentile recorded in the medical record) (SGA = Small for Gestational Age, AGA = Appropriate for Gestational Age, LGA = Large for Gestational Age), need for admission to the NICU or joint accommodation and type of feeding (Breastfeeding, Exclusive Breastfeeding). Regarding the socioeconomic strata, the individuals were grouped in $A B, C$ and DE classes, according to 2016 rules of the Brazilian Association of Research Companies (ABEP).

The health conditions of the infants were assessed through the perception of the main caregivers (who answered the questionnaire). This perception was considered important, as families/caregivers monitor the health conditions of the infants and recognize the intensity and the implication of these problems to the infants' health and to the family routine. The evaluations were carried out with an instrument that assesses quality of life, validated for use in Brazil in children under five years old, using the items for the evaluation of the acute health condition (Cronbach's a> $0.9)^{(12)}$. In the translation and validation process, the authors recommend the use of the instrument for children under 5 years of age. Therefore, we consider its use pertinent, since in an empirical search, no instruments were found to measure this investigated outcome, perceived by the caregivers. The instrument is a Likert-type scale, in which health conditions were assessed and classified according to the scores [Intensity of the disease in the caregiver's perception]. Responses ranged from never $=0[\mathrm{~N}]$, almost never $=1[\mathrm{AN}]$, almost always $=2[\mathrm{AA}]$ and always $=3[\mathrm{~A}]$. The scale suggests quarterly assessments and portrays the intensity of the injuries 
in the last three months, according to the respondent's perception (main caregiver).

Acute health problems [Skin Allergy (Eczema, outcome variable) and other respiratory and gastrointestinal conditions (independent)] were analyzed according to the score of the last three months, according to the instrument definition ${ }^{(12)}$. Skin allergies (Eczema) were described according to the definitions and clinical manifestations perceived by caregivers/respondents: vesicular lesions (blisters), secretions (secretion), erythematous (redness) and or crusted, which could be atypical or contact lesions ${ }^{(4)}$. In the comparison of frequencies and odds ratio, respiratory [Bronchitis, Breathing Difficulty and Cough] and gastrointestinal disorders [Colic (only in the $3^{\text {rd }}$ month), Vomiting and Diarrhea] were analyzed in the comparison of the intensity of Skin Allergy (Eczema). When comparing neonatal, socioeconomic factors and other health conditions, the dichotomized variables were considered as follows: intensities Always, Almost Always and Almost Never as variable Yes $[\mathrm{Y}]$ considering the development of the health problem; and Never [N], for those who did not develop the condition ${ }^{(12)}$.

In the comparison of Skin Allergy (Eczema) with neonatal, socioeconomic and other acute health problems (respiratory and gastrointestinal), analyzes occurred only in the $3^{\text {rd }}$ and $12^{\text {th }}$ months of life, to portray the first and last quarters of the first year of life. In the correlation of the intensity of skin allergy, data from the $3^{\text {rd }}, 6^{\text {th }}, 9^{\text {th }}$ and $12^{\text {th }}$ months of life were used throughout the first year.

Chi-Square test and Fisher's exact test were used for the analysis of the variables associated with the frequency of acute conditions in the SPSS software, version 20.0. A statistically significant association was established with the outcome and with variables whose $p$-value was less than or equal to $5 \%(p \leq 0.05)$. Comparisons of answers Yes $[\mathrm{Y}]$ and Never [N] (dichotomous) and 95\% Confidence Interval (Cl) were used in Odds Ratio (OR) analysis. In the correlation between the intensities showed [Never, Almost Never, Almost Always and Always] in each quarter assessed, Pearson's correlation was used, due to the characteristics of the data after normality tests used (Shapiro-Wilk and Kolmogorov). A significance level of $p$ equal to or less than $5 \%(p \leq 0.05)$ was also used.

The study complied with the ethical recommendations and was approved by the Consolidated Opinion of the Research Ethics Committee of the Universidade Federal de Santa Maria, under no 1.511.201/2016, and
Certificate of Presentation for Ethical Appreciation no 53898916.9.0000.5346.

\section{RESULTS}

The prevalence of intensity Always in the population of moderate and late preterm infants, for skin allergy, according to the perception of the main caregiver was 16\% $(n=19)$ in the assessment of the $3^{\text {rd }}$ month and $30.5 \%$ at 12 months. Comparison of neonatal and socioeconomic factors associated with the development of the condition that explains the frequency of Skin Allergy (Eczema) in the third month of life, as perceived by the main caregiver is shown in Table 1.

It should be noted that newborn infants in the NICU, at three months, were 3.2 times more likely to develop skin allergy (Eczema) compared to newborn babies in Joint Accommodation. The other factors showed no significant difference. As for the associated factors in the $12^{\text {th }}$ month assessment, they are shown in Table 2 .

Not being breastfed was a factor that contributed to a 4.31-fold increase in the probability of developing skin allergy (Eczema) in the 12th month of life. The relationship between the other acute conditions and the development of skin allergy, according to the caregiver's perception, in the $3^{\text {rd }}$ and $12^{\text {th }}$ months of life, is shown in Tables 3 and 4, respectively.

Premature infants who had colic in the $3^{\text {rd }}$ month and diarrhea in the $3^{\text {rd }}$ and $12^{\text {th }}$ months of life were more likely to develop skin allergy. Infants who had colic at 6 months and diarrhea at 12 months were 4.5 and 4.6 times more likely to develop skin allergy, respectively.

Regarding respiratory problems, the relationship was present in the three symptoms presented. Premature infants who had bronchitis and cough were 6.4 and 4.8 times more likely to develop skin allergy in the first 12 months of life, respectively. Skin allergy is associated with other health problems. The correlation of intensity (Never, Almost Never, Almost Always, Always), during the first year of life is shown in Table 5.

The severity of skin allergy in the first year of life is inversely proportional to age, as it is reduced with increase in age, that is, the severity of allergy in the third month correlates with that of the other months, and the strength of the correlation decreases over the months $\left(\mathrm{Cl} 6^{\text {th }}\right.$ month: 0.541 ; $\mathrm{Cl} 9^{\text {th }}$ month 0.406 and $\mathrm{Cl} 12^{\text {th }}$ month: 0.348$)$, but remains significant $(p<0.001)$. 
Table 1 - Neonatal and socioeconomic factors associated with the frequency of Skin Allergy (Eczema) in moderate and late preterm infants in the 3rd month of life. Santa Maria, RS. Brazil. 2020

\begin{tabular}{|c|c|c|c|}
\hline \multirow{2}{*}{$3^{\text {rd }}$ month $(\mathrm{N}=119)$} & \multicolumn{3}{|c|}{ Developed Skin Allergy (Eczema) } \\
\hline & n (\%) & Odds Ratio (Cl 95\%) & p-value \\
\hline \multicolumn{4}{|l|}{ Gestational age } \\
\hline Moderate Preterm $(n=18)$ & $5(27.8)$ & $1.181(0.893-1.561)$ & $0.130^{*}$ \\
\hline Late Preterm $(n=101)$ & 14(13.9) & 1 & \\
\hline \multicolumn{4}{|l|}{ Birth weight and Gestational Age } \\
\hline Small for Gestational Age $(n=24)$ & $4(16.7)$ & $0.938(0.280-3.134)$ & $0.917^{* *}$ \\
\hline $\begin{array}{l}\text { Appropriate or Large for Gestational } \\
\text { Age }(n=95)\end{array}$ & 15(15.8) & 1 & \\
\hline \multicolumn{4}{|l|}{ Unit where NB was admitted } \\
\hline Neonatal Intensive Care Unit $(n=48)$ & $13(27.1)$ & $3.205(1.309-7.846)$ & $0.006^{*}$ \\
\hline Joint Accommodation $(n=71)$ & $6(8.5)$ & 1 & \\
\hline \multicolumn{4}{|l|}{ Breastfeeding } \\
\hline Not breastfed $(n=12)$ & $3(25.0)$ & $1.134(0.810-1.587)$ & $0.404^{* *}$ \\
\hline Exclusive Breastfeeding $(n=107)$ & $16(15)$ & 1 & \\
\hline \multicolumn{4}{|l|}{ Exclusive Breastfeeding } \\
\hline Exclusive Breastfeeding $(n=55)$ & $7(12.7)$ & $1.582(0.576-4.351)$ & $0.370^{*}$ \\
\hline$n=64)$ & 12(18.8) & 1 & \\
\hline \multicolumn{4}{|l|}{ Socioeconomic stratum (ABEP criteria) } \\
\hline$A-B(n=21)$ & $4(19.0)$ & $0.768(0.227-2.602)$ & $0.671^{* *}$ \\
\hline C, $D-E(n=98)$ & 15(15.3) & 1 & \\
\hline TOTAL & 19(16.0) & & \\
\hline
\end{tabular}

Source: Research data, 2020.

${ }^{*}$ Chi-square test; ** Fisher's Exact test.

\section{DISCUSSION}

Newborn infants face numerous challenges in their adaptation to extrauterine life. Therefore, their delicate and underdeveloped skin requires special attention, and this care contributes to the prevention of skin disorders and conditions, such as eczema and skin allergies. A study with 155 full-term infants aged 0-3 months found that $18.1 \%$ had atopic dermatitis/eczema up to 2 years of age, and this data is similar to the prevalence described in the present study. Likewise, some factors such as family history of the skin condition and being male were significantly associated with atopic dermatitis/eczema ${ }^{(13)}$.

According to the findings, non-breastfed babies had a significantly higher incidence of development of skin allergy compared to those who were breastfed only until the end of 
Table 2 - Neonatal and socioeconomic factors associated with the frequency of Skin Allergy (Eczema) in moderate and late preterm infants in the $12^{\text {th }}$ month of life. Santa Maria, RS. Brazil. 2020

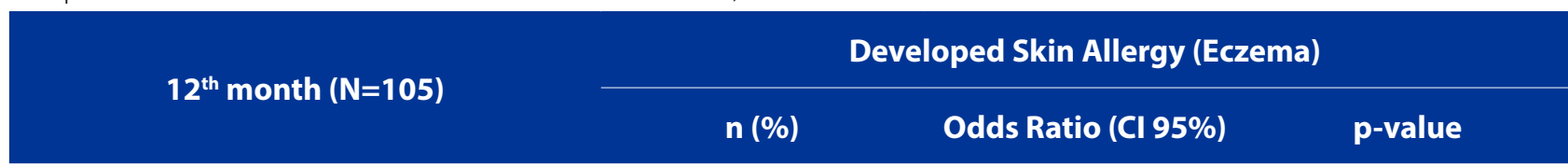

\section{Gestational Age}

Moderate Preterm $(n=17)$

Late Preterm $(n=88)$

\section{Birth weight and Gestational Age}

Small for Gestational Age $(n=22)$

$8(36.4)$

24(28.9)

Appropriate or Large for Gestational

Age $(n=84)$

\section{Unit where NB was admitted}

Neonatal Intensive Care Unit $(\mathrm{n}=42)$

16(38.1)

16(25)

Joint Accommodation ( $n=63$ )

\section{Breastfeeding}

Not breastfed $(n=8)$

Breastfeeding $(n=7)$

$27(27,8)$

\section{Socioeconomic stratum (ABEP criteria)}

$A-B(n=21)$

6(30)

$1.028(0.356-2.973)$

$0.959^{*}$
C, D-E $(n=98)$

TOTAL

26(30.6)

Source: Research data, 2020.

Chi-square test: ** Fisher's Exact test.

the first year of life. Encouraging breastfeeding throughout the pregnancy-puerperal cycle, in addition to providing a first contact between the mother-child binomial, favors adaptation to extrauterine life and thermal regulation, cardio-respiratory stability and adequate blood glucose levels in newborn babies. The manifestation of food disorders/ allergies or inadequate food supply can cause skin problems, especially in premature infants ${ }^{(14)}$. It is also recognized that eating disorders and their impact on skin are rare in breastfed babies, as there is a protective factor for breastfeeding in this outcome ${ }^{(15)}$.
In contrast, a study found that early weaning did not pose a risk for atopic dermatitis for the infants when these were compared to infants who were exclusively breastfed. Also, prolonged maintenance of partial breastfeeding (breast milk and formula) was not associated with atopic dermatitis in the infant population ${ }^{(16)}$. However, it is recognized that the maintenance of breastfeeding implies numerous benefits. The present study showed that non-breastfeeding is a risk factor for babies and reported the other benefits of breastfeeding already consolidated in the literature, such as protection against gastrointestinal and respiratory infections, reduced 
Table 3 - Relationship between the frequency of respiratory and gastrointestinal disorders with the frequency of Skin Allergy (Eczema) in moderate and late preterm infants in the $3^{\text {rd }}$ month of life - 2016-2018. Santa Maria, RS. Brazil. 2020

\begin{tabular}{|c|c|c|c|}
\hline \multirow{2}{*}{$3^{\text {rd }}$ Month $(\mathrm{N}=119)$} & \multicolumn{3}{|c|}{ Developed Skin Allergy (Eczema) } \\
\hline & n (\%) & p-value & Odds Ratio (Cl 95\%) \\
\hline Colic [Y] $(n=70)$ & 16(22.9) & $0.01^{* *}$ & $4.543(1.245-16.576)$ \\
\hline Colic $[N](n=49)$ & $3(6.1)$ & & 1 \\
\hline Diarrhea $[Y](n=33)$ & $9(27.3)$ & $0.03^{*}$ & $2.850(1.037-7.831)$ \\
\hline Diarrhea $[N](n=86)$ & 10(11.6) & & 1 \\
\hline Vomiting $[Y](n=63)$ & $9(14.3)$ & $0.59^{*}$ & $0.696(0.208-2.328)$ \\
\hline Vomiting $[N](n=56)$ & 10(17.9) & & 1 \\
\hline Bronchitis $[Y](n=14)$ & $7(50.0)$ & $<0.01^{*}$ & $7.750(2.316-25.935)$ \\
\hline Bronchitis $[N](n=105)$ & 12(11.4) & & 1 \\
\hline $\mathrm{RD}[\mathrm{Y}](\mathrm{n}=36)$ & $6(31.6)$ & $0.891^{*}$ & $1.077(0.374-3.101)$ \\
\hline $\mathrm{RD}[\mathrm{N}](\mathrm{n}=83)$ & $30(30.0)$ & & 1 \\
\hline Cough $[Y](n=56)$ & 11(19.6) & $0.302^{*}$ & $1.681(0.623-4.533)$ \\
\hline Cough $[N](n=63)$ & $8(12.7)$ & & 1 \\
\hline
\end{tabular}

Source: Research data, 2020

[Y] Yes; [N]: Never. RD: Respiratory Difficulty.

${ }^{*}$ Chi-square test; ** Fisher's Exact test.

Table 4 - Relationship between the frequency of respiratory and gastrointestinal disorders with the frequency of Skin Allergy (Eczema) in moderate and late preterm infants in the $12^{\text {th }}$ month of life. Santa Maria, RS. Brazil 2016-2018

\begin{tabular}{lccc}
\multicolumn{1}{c}{$\mathbf{1 2}^{\text {th }}$ Month } & \multicolumn{3}{c}{ Developed Skin Allergy (Eczema) } \\
\cline { 2 - 4 } & $\mathbf{n}(\mathbf{N}=\mathbf{1 0 5})$ & p-value & Odds Ratio (Cl 95\%) \\
\hline Diarrhea $[\mathrm{S}](\mathrm{n}=29)$ & $16(55.2)$ & $<0.01^{*}$ & $4.615(1.846-11.539)$ \\
Diarrhea $[\mathrm{N}](\mathrm{n}=76)$ & $13(21.1)$ & & 1 \\
Vomiting $[\mathrm{Y}](\mathrm{n}=31)$ & $15(48.4)$ & $0.01^{*}$ & $3.143(1.293-7.644)$ \\
Vomiting $[\mathrm{N}](\mathrm{n}=74)$ & $17(23.0)$ & & 1 \\
Bronchitis $[\mathrm{Y}](\mathrm{n}=20)$ & $13(65.0)$ & $<0.01^{*}$ & $6.451(2.255-18.454)$ \\
Bronchitis $[\mathrm{N}](\mathrm{n}=85)$ & $19(22.4)$ & & 1 \\
RD $[\mathrm{Y}](\mathrm{n}=25)$ & $12(37.5)$ & $0.029^{*}$ & $2.769(1.089-7.044)$ \\
RD $[\mathrm{N}](\mathrm{n}=80)$ & $13(17.8)$ & & 1 \\
Cough $[\mathrm{Y}](\mathrm{n}=52)$ & $24(46.2)$ & $<0,01^{*}$ & $4.821(1.904-12.206)$ \\
Cough $[\mathrm{N}](\mathrm{n}=53)$ & $8(15.1)$ & & 1 \\
\hline
\end{tabular}

Source: Research data, 2020

[Y] Yes; [N]: Never. RD: Respiratory Difficulty.

${ }^{*}$ Chi-square test; *** Fisher's Exact test. 
Table 5 - Correlation of skin allergy intensity over the first year of life of moderate and late preterm infants - 2016-2018. Santa Maria, RS. Brazil. 2020

\begin{tabular}{|c|c|c|c|c|}
\hline & $\begin{array}{c}\text { Correlation } \\
3^{\text {rd }} \text { Month }\end{array}$ & $\begin{array}{c}\text { Correlation } \\
6^{\text {th }} \text { Month }\end{array}$ & $\begin{array}{c}\text { Correlation } \\
9^{\text {th }} \text { Month }\end{array}$ & $\begin{array}{l}\text { Correlation } \\
12^{\text {th }} \text { Month }\end{array}$ \\
\hline Correlation $3^{\text {rd }}$ Month & - & - & - & - \\
\hline Pearson & & 0.541 & 0.406 & 0.348 \\
\hline$p$-value & $x$ & $<0.001$ & $<0.001$ & $<0.001$ \\
\hline Correlation $6^{\text {th }}$ Month & - & - & - & - \\
\hline Pearson & 0.541 & X & 0.43 & 0.383 \\
\hline$p$-value & $<0.001$ & & $<0.001$ & $<0.001$ \\
\hline Correlation $9^{\text {th }}$ Month & - & - & - & - \\
\hline Pearson & 0.406 & 0.43 & X & 0.701 \\
\hline$p$-value & $<0.001$ & $<0.001$ & & $<0.001$ \\
\hline Correlation $12^{\text {th }}$ Month & - & - & - & - \\
\hline Pearson & 0.348 & 0.383 & 0.701 & X \\
\hline$p$-value & $<0.001$ & $<0.001$ & $<0.001$ & \\
\hline
\end{tabular}

Source: Research data, 2020

risk of obesity and a positive effect on the development of the oral cavity. Moreover, this practice can minimize allergic signs and symptoms or their progression, as well as child malnutrition and hence reduces health risk in adulthood ${ }^{(6)}$.

Lower gestational age was not a predictive factor for increased prevalence of skin allergies. The infants in the NICU were more likely to develop such allergies. This finding may reflect the exposure of babies during hospitalization, as well as possible clinical and therapeutic impacts related to hospitalization. Skin lesions are often identified in neonates admitted to NICUs ${ }^{(17)}$. In full-term babies the stratum corneum is only fully developed at the end of the third pregnancy trimester, and the epidermal barrier function of premature babies is impaired. There is increased transepidermal water loss that can lead to dehydration, thermal instability and electrolyte imbalance in premature infants. Therefore, the fragility of the skin barrier deserves considerable attention, in order to provide comfort, safety and well-being to the babies $^{(2,17)}$. In contrast, an international study showed inverse association between the development of eczema and extreme prematurity ${ }^{(10)}$.
The prevalence of skin disorders, such as atopic dermatitis, has increased worldwide, reaching approximately $20 \%$ of the child population. Environmental factors can contribute to the increase in cases of skin diseases. However, other elements also impact this scenario, such as outdoor circulation and interaction with animals, contact with air pollution, climate and food diet, among others ${ }^{(18)}$. The management of care and the constant assessment of the risks and possibilities of injuries and complications by a well-trained health team may contribute to reduce the onset of neonatal skin lesions, especially in premature babies, and their effects on skin integrity and skin response, throughout the first year of life.

In the last trimester of pregnancy, the fetal immune system seeks to adapt to tolerate the maternal immune system and to carry out postnatal immune defense, acquiring passive immunity from the mother. Premature infants are exposed to different olfactory and gustatory stimuli that contribute to inadequate stimulation of their chemosensory system. They may also develop bronchial asthma more frequently, although atopic dermatitis and skin disorders in prematurity should be better clarified in the literature ${ }^{(19)}$. 
Regarding the significant correlation of severity of skin problems with aging in the first year of life, the evidence corroborates this finding, as skin problems are more severe when babies get older. After the period of lactation and food transition, the prevalence remains constant until adolescence and the beginning of adulthood ${ }^{(5,20)}$.

Environmental exposure to allergens increases and hence prevalence tends to rise. More than 10\% of children up to 5 years of age are affected by an allergic disorder reported by their parents. The relationship between the development of eczema and/ or asthma and late introduction of solid foods were predictors of allergy reported by the parents. Thus, the skin disorders vary a lot and have associated and multi-symptom causes ${ }^{(20)}$.

Most guidelines on neonatal skin care and its health problems, whether allergic or physical, are based on aspects related to healthy and full-term babies. However, there are still few studies on the maintenance of the skin barrier in premature babies, as well as on allergic reactions and diverse skin conditions and on the relationships and implications for babies with other health problems $s^{(2,4)}$.

Broader knowledge of the medium and long-term effects of premature birth on the immune system is necessary, so that further information on therapeutic and technological approaches to reduce the risk and complications arising from skin allergies and lesions in premature infants, especially during the first year of life ${ }^{(19)}$, is obtained.

\section{CONCLUSION}

Moderate and late preterm infants in the NICU who were not breastfed are more likely to develop skin allergy in the $3^{\text {rd }}$ and $12^{\text {th }}$ months of life. According to the caregivers, the development of skin allergy is more intense in newborn infants who have clinical respiratory and gastrointestinal manifestations, indicating the complex nature of the disorder, whether it is a conditioning or cause-effect condition.

Therefore, this population must be properly identified in health services, through the guarantee of access to childcare consultations. Also, newborns in the NICUs and those who are not being breastfed must be carefully monitored, as this population is at greater risk for the development of skin allergies. The complex scenario of prematurity requires health professionals, especially nurses, to implement safe interventions that reduce the likelihood of skin disorders, such as the encouragement and implementation of EBF and early recognition of respiratory and gastrointestinal disorders as a possible cause-effect of skin complications.

A limitation of the present study is the approach of the perceptions of main caregivers, typically the mothers' perceptions, under a threshold analysis for categorical data. However, the implications of health problems are experienced by the families of the newborn infants and therefore they can provide a consistent report of the implications of these conditions on their daily lives and on the health of their children. Future research on the implications of intensive care as an aggravating factor in the development of skin allergies, as well as on the association of medical conditions (respiratory and gastrointestinal disorders) with skin allergies and on the need for specialized services and the possible chronicity of this condition over the years, is suggested.

\section{$\square$ REFERENCES}

1. World Health Organization (CH). Survive and thrive: transforming care for every small and sicknewborn. Geneva:WH0; 2019 [cited 2020 Jun 25]. Available from: https://apps.who.int/iris/bitstream/handle/10665/326495/9789241515887eng.pdf?ua=1

2. Kusari A, Han AM, Virgen CA, Matiz C, Rasmussen M, Friedlander SF, et al. Evidence-based skin care in preterm infants. Pediatr Dermatol. 2019;36(1):16-23. doi: https://doi.org/10.1111/pde. 13725

3. Alves JQN, Mendes JFR, Jaborandy ML. Perfil nutricional e consumo dietético de crianças alérgicas à proteína do leite de vaca acompanhadas em um hospital infantil de Brasilia/DF, Brasil. Com Ciênc Saúde. 2017 [cited 2019 May 05];28(3/4):40212. Available from: http://bvsms.saude.gov.br/bvs/periodicos/ccs_artigos/ v28_3_perfil_nutricional_consumo.pdf

4. Ministério da Saúde (BR). Secretaria de Políticas de Saúde. Departamento de Atenção Básica. Área Técnica de Dermatologia Sanitária. Dermatologia na Atenção Básica de Saúde. Brasilia: Ministério da Saúde; 2002 [cited 2019 May 05]. Available from: https://bvsms.saude.gov.br/bvs/publicacoes/guiafinal9.pdf

5. Abuabara K, Yu AM, Okhovat JP, Allen IE, Langan SM. The prevalence of atopic dermatitis beyond childhood: a systematic review and meta-analysis of longitudinal studies. Allergy. 2018;73(3):696-704. doi: https://doi.org/10.1111/ all. 13320

6. Woon FC, Chin YS, Ismail IH, Chan YM, Batterham M, LatiffAHA, et al. Contribution of early nutrition on the development of malnutrition and allergic diseases in the first year of life: a study protocol for the Mother and Infant Cohort Study (MICOS). BMC Pediatr. 2018;18:233. doi: https://doi.org/10.1186/s12887-018-1219-3

7. Apfelbacher CJ, Diepgen TL, Schmitt J. Determinants of eczema: population-based cross-sectional study in Germany. Allergy 2011;66(2):206-13. doi: https://doi. org/10.1111/j.1398-9995.2010.02464.x

8. Hale G, Davies E, Grindlay DJC, Rogers NK, Harman KE. What's new in atopic eczema? an analysis of systematic reviews published in 2017. Part 2: epidemiology, aetiology and risk factors. Clinical and Experimental Dermatology. 2019;44(8):868-73. doi: https://doi.org/10.1111/ced.14075

9. Leite RMS, Leite AAC, Costa IMC. Dermatite atópica: uma doença cutânea ou uma doença sistêmica? A procura de respostas na história da dermatologia. An Bras Dermatol. 2007;82(1):71-8. doi: https://doi.org/10.1590/ S0365-05962007000100010

10. Winslow A. The very preterm neonate's role in prevention of atopic disease. J Allergy Clin Immunol. 2019;143(5):1972. doi:https://doi.org/10.1016/j.jaci.2019.01.035

11. Medronho R. Epidemiologia. 3a ed. Rio de Janeiro: Atheneu; 2011. 
12. Tompsen AM. Adaptação e avaliação de um instrumento para medir qualidade de vida em crianças a partir de oito meses de idade até cinco anos [dissertação]. Porto Alegre (RS): PUCRS; 2010 [cited 2018 Mar 07]. Available from: https:// tede2.pucrs.br/tede2/bitstream/tede/1348/1/425161.pdf

13. Johnson DE. Extremely preterm infant skin care: a transformation of practice aimed to prevent harm. Adv Neonatal Care. 2016 Suppl 5S:S26-S32. doi: https://doi. org/10.1097/anc.0000000000000335

14. Siqueira SMC, Camargo CL, Santos JB, Silva JuniorWM, Santos CF, Canavarro DA. A amamentação como fator de proteção para a alergia à proteína do leite de vaca na infância: 0 que dizem as evidências científicas? Rev Eletrôn Acervo Saúde. 2020;(49):e485. doi: https://doi.org/10.25248/reas.e485.2020

15. Rajani PS, Martin H, Groetch M, Järvinen KM. Presentation and management of food allergy in breastfed infants and risks of maternal elimination diets. J Allergy Clin Immunol Pract. 2020;8(1):52-67. doi: https://doi.org/10.1016/j. jaip.2019.11.007

\section{- Authors' contribution:}

Conceptualization: Leonardo Bigolin Jantsch, Eliane Tatsch Neves.

Formal analysis: Leonardo Bigolin Jantsch, Andrea

Moreira Arrué, Eliane Tatsch Neves.

Investigation: Leonardo Bigolin Jantsch, Andrea Moreira Arrué, Diúlia Calegari de Oliveira, Eliane Tatsch Neves. Methodology: Leonardo Bigolin Jantsch, Bruna Paola de Lima Bridi, Andrea Moreira Arrué, Diúlia Calegari de Oliveira, Eliane Tatsch Neves.

Validation: Leonardo Bigolin Jantsch, Giovana Dornelles Callegaro Higashi, Andrea Moreira Arrué, Eliane Tatsch Neves.

Writing - original draft: Leonardo Bigolin Jantsch, Bruna Paola de Lima Bridi, Giovana Dornelles Callegaro Higashi, Andrea Moreira Arrué, Diúlia Calegari de Oliveira.

Writing - review and editing: Leonardo Bigolin Jantsch, Paola de Lima Bridi, Giovana Dornelles Callegaro

Higashi, Andrea Moreira Arrué, Eliane Tatsch Neves.
16. Lin B, Dai R, Lu L, Fan X, Yu Y. Breastfeeding and atopic dermatitis risk: a systematic review and meta-analysis of prospective cohort studies. Dermatology. 2020;236(4):345-60. doi: https://doi.org/10.1159/000503781

17. Broom M, Dunk AM, Mohamed ALE. Predicting neonatal skin injury: the first step to reducing skin injuries in neonates. Health Serv Insights. 2019;12:1178632919845630. doi: https://doi.org/10.1177/1178632919845630

18. Bonamonte D, Filoni A, Vestita M, Romita P, Foti C, Angelini G. The role of the environmental risk factors in the pathogenesis and clinical outcome of atopic dermatitis. BioMed Res Int. 2019:2450605. doi: https://doi. org/10.1155/2019/2450605

19. Goedicke-FritzS, Härtel C, Krasteva-ChristG, Kopp MV, Meyer S, Zemlin M. Preterm birth affects the risk of developing immune-mediated diseases. Front. Immunol. 2017;8:1266. doi: https://doi.org/10.3389/fimmu.2017.01266

20. Weidinger S, Gupta AK. Atopic dermatitis. Lancet. 2016;387(10023):1109-22. doi: https://doi.org/10.1016/S0140-6736(15)00149-X

\section{- Corresponding author:}

Leonardo Bigolin Jantsch

Email: leo_jantsch@hotmail.com

\section{Associate editor:}

Wiliam Wegner 